\title{
Author Correction: Advances in artificial spin ice
}

\author{
Sandra H. Skjcervø, Christopher H. Marrows (D), Robert L. Stamps (1) and Laura J. Heyderman (D)
}

Nature Reviews Physics 2, 13-28 (2020) https://doi.org/10.1038/s42254-019-0118-3 Published online 8 November 2019

This article was originally published with an error in Figure 6. The central schematic "Artificial spin ice" had the right-most spin arrow pointing in the wrong direction. This arrow has now been reversed, to correctly depict a geometrically frustrated spin configuration.

https://doi.org/10.1038/s42254-020-0148-x I Published online 20 January 2020

๑) Springer Nature Limited 2020 